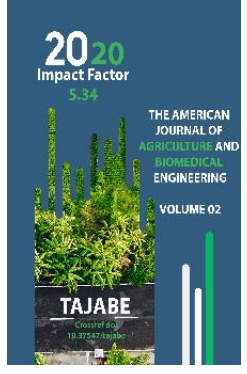

\title{
Scientific Basis For Increasing Soil Fertility And Its Culture
}

Nafisa Abdimannobovna Mamadjonova

Doctor Of Philosophy In Agricultural Sciences, Senior Lecturer, Andijan Institute Of Agriculture And Agrotechnology, Uzbekistan

Journal Website:

http://usajournalshub.c

om/index,php/tajabe

Copyright: Original content from this work may be used under the terms of the creative commons attributes 4.0 licence.

\section{ABSTRACT}

This article mainly discusses the scientific basis of soil fertility and increasing its culture. The division of soil fertility into natural and artificial species is described in the article. Natural fertility occurs under the influence of natural factors. The level of soil fertility, that is, the ability of the soil to yield to one degree or another, depends on natural factors and historical reasons. Natural factors, such as climate, vegetation cover, soil mineral composition, determine the natural fertility level of the soil. Natural fertility occurs without human intervention. It is mainly characteristic of natural crops, and usually the level of such fertility is low or high, depending on the organic and mineral composition, chemical, biological, biochemical properties of the soil.

\section{KEYWORDS}

Soil fertility, natural factors, vegetation cover, biological, chemical and physical methods, agricultural culture.

\section{INTRODUCTION}

Decree of the President of the Republic of Uzbekistan No PD-5635 of January 17, 2019 "On the State Program for the implementation of the Action Strategy for the five priority areas of development of the Republic of Uzbekistan in 2017-2021 in the Year of Active Investment and Social Development" and Ensuring the 
implementation of the Resolution No. PD-4239 of March 14, 2019 "On measures to develop agricultural cooperation in the field of fruit and vegetables" and maintaining and increasing soil fertility, continuous monitoring of soil nutrient content in agricultural lands, In order to develop agrochemical cartograms to determine the scientific demand for mineral fertilizers, the Cabinet of Ministers decides:

creation of electronic cartograms on the level of nutritional provision of the soil of irrigated agricultural lands, creation of an agrochemical database with the wide use of modern technologies of geographic information systems, analysis of their periodic changes;

taking samples of soil and agricultural products in the field, analyzing the amount of pesticide and nitrate residues in them, and providing agricultural producers with certificates indicating the amount of pesticide and nitrate residues in agricultural products;

proceeding from a number of tasks, such as the creation of special modern stationary and mobile laboratories for the chemical analysis of mineral and organic fertilizers in water and plants, they set the current tasks for the researcher.

During his visit to Andijan region, President Shavkat Mirziyoyev spoke about improving the ecological situation in the region, rational use of land and water resources, increasing soil fertility, acclimatization of crops suitable for valley conditions, emphasizing the development of shade in the region.

Indeed, agriculture is one of the main sectors of agriculture, providing the population with food, industry with raw materials, and livestock with fodder. It serves to teach the methods of care for crops in order to obtain high quality and high yields, measures to increase soil fertility by physical and biological means.

According to Article 55 of the Constitution of the Republic of Uzbekistan, natural objects, including land, are a national treasure and are under state protection. Efficient use of land on the basis of scientific recommendations, proper protection of it is undoubtedly one of the key factors in the development of agriculture.

\section{MAIN PART}

Comprehensive soil improvement, increasing yields and economic efficiency is one of the important issues for the future development of agriculture.

The correct and effective use of any means of production largely depends on a deep and comprehensive study of its most important properties. This primarily applies to the soil, its rational use, increasing soil fertility, knowledge of soil quality, grading, economic value, protection, tillage methods, fertilization, based on the physical properties of the soil, the use of a certain technological sequence of favorable agro-technical terms, soil erosion, measures against salinization, condensation, etc., require that certain elements be governed by clear legislation. Adoption of laws and regulations of the Republic of Uzbekistan "Land Code", "Law on Land Cadastre" and other legal provisions in the agricultural sector in the current situation. The "Program for Deepening Agricultural Reforms" creates a legal basis for the rational use, protection of land, scientific support of agriculture.

Land is the main and irreplaceable means of production in agriculture. Due to the correct use of the means of production, land fertility increases, this ensures the further 
development of agriculture. One of the main tasks of agriculture is to use the resources of the sacred land wisely and efficiently.

High and stable yields of crops and increase labor productivity in production depend directly on the level of soil fertility and agricultural culture.

Soil fertility refers to the ability of a plant to provide water and nutrients throughout the entire (vegetation) growth period. Due to this property, the soil is very different from natural rocks, rocks, sand and others.

Man constantly uses the fertile properties of the soil and influences its structural changes in order to obtain high yields from crops.

The development of all sectors of agriculture depends on soil fertility. Therefore, soil is the main means of agricultural production and caring for soil fertility is the daily task of all people involved in agriculture.

Soil fertility improves when it is wisely exposed to the soil, and decreases when it is treated improperly.

In the primitive system, farmers encountered and used the natural fertility of the soil in their practical activities.

As a result of processes such as human tillage, irrigation, fertilization, man has changed the level of natural fertility and created its artificial fertility. That is, artificial fertility is created by man. Using advances in science and technology, man is changing the natural properties of the soil. Soil fertility is also divided into potential and effective fertility. Potential fertility refers to the total amount of nutrients in the soil. Effective fertility is determined by the amount of nutrients a plant can absorb from the soil.
Artificial or effective fertility is formed with the participation of human activity and depends on the increase in nutrients in the soil by a person, water supply, and improvement of the physical properties of the soil. Consequently, soil fertility is directly related to the social, economic system, the development of science, technology, the development of productive forces.

Natural fertility is constantly replenished under the influence of human activity. However, if a person does not take proper care of soil fertility or is unable to maintain it at a certain level, effective fertility can also fall below the level of natural fertility.

Ways to increase the effective fertility of the soil are diverse. Measures such as optimal tillage, use of fertilizers and various reclamation measures, crop rotation, scientific organization of land use, improvement of the ecological condition of the soil will dramatically increase the efficiency of soil fertility.

Cultivated soil is a soil with good agrochemical and agrophysical properties, due to which the water, air, heat and nutrient regimes are good, creating favorable conditions for normal growth and development of crops.

Land is cultivated mainly by biological, chemical and physical methods.

Biological method - in this case, measures should be taken to control the synthesis and decomposition of organic matter in the soil, planting high-yielding varieties resistant to diseases and pests, and introducing crop rotations.

Chemical method - in which the soil is filled with various mineral, bacterial fertilizers, gypsum and other substances are applied, 
increasing the amount of substances in the soil that are easily absorbed by the plant. When the soil is limed, the acidity of the soil is normalized, and when it is plastered, the alkalinity is normalized, creating a good environment for plant growth.

Physical method - in which the soil is exposed to physical and mechanical stress, that is, the soil is subjected to various treatments, soil structure and a set of measures to control its air, heat, water and other modes. In addition, the physical method also includes collectordrainage works on enlargement of small maps, removal of soil debris, saline leaching, lowering of groundwater levels, as well as presowing and post-sowing furrows and furrows. In addition, the mechanical composition can be sprinkled with sand on heavy soils, calcification (suppression of turbidity) on light soils.

The level of fertility and culture of the soil is determined by the amount of humus in it, the amount of microorganisms, soil environment, granularity, hardness and softness, structure, thickness of the tillage layer and other indicators.

Organic fertilizers, mainly manure, are important in soil cultivation. Regular fertilization of soils increases the amount of humus, nitrogen, phosphorus and potassium in the soil, increases its absorption capacity, saturation with bases, nitrification ability, many microorganisms fall to the soil with local fertilizers, and they also play an important role in soil cultivation.
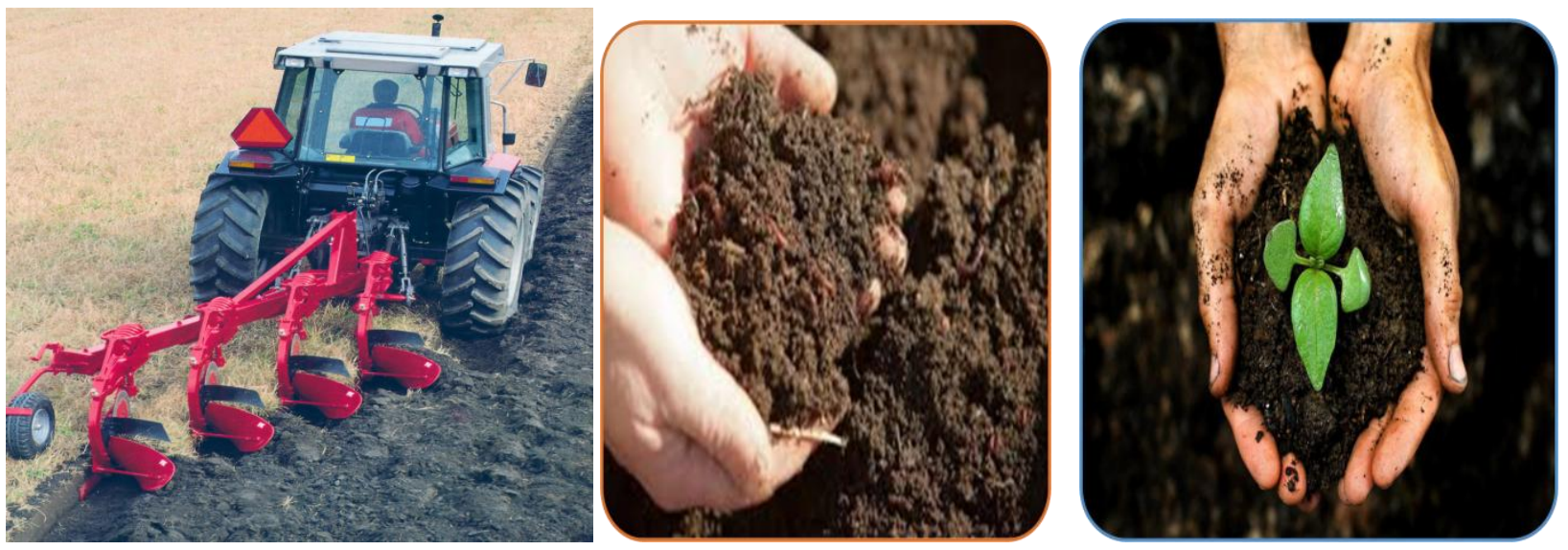

\section{CONCLUSION}

When farming culture is low, there are many weed seeds and their growing organs in the tillage layer of the soil. They serve as a major source of crop contamination. Due to the abundance of weed seeds and growth organs, non-adherence to crop rotation, untimely quality tillage, failure to care for crops on the basis of high agronomic techniques, failure to introduce special measures to control weeds, untimely harvest and so on. The thicker and more fertile the topsoil, the deeper the root system of plants will grow and become more productive. 
Doi: https://doi.org/10.37547/tajabe/Volume02Issue08-05

\section{REFERENCES}

1. Mamadjonova N.A. Water and resourcesaving agrotechnologies for the cultivation of soil varieties in the conditions of gray soils. Journal of Critical Reviews ISSN- 2394-5125 VOL 7, ISSUE 15, 2020. DOI:

http://dx.doi.org/10.31838/jcr.07.14.196

2. Mamadjonova N.A. Melioration ecology. Life Sciences and Agriculture №2.2. 2020. -pp. 105-108.

3. Mamadjonova N.A. Resource-saving technology. Indonesian Journal of Innovation Studies. Vol 8. 2019. October. Innovation in Agricultural Science 